\title{
К ВОПРОСУ О ПОВЫШЕНИИ ЭФФЕКТИВНОСТИ РЕАБИЛИТАЦИИ БОЛЬНЫХ, НУЖДАЮЩИХСЯ В СЬЁМНОМ ПРОТЕЗИРОВАНИИ (ИССЛЕДОВАНИЕ IN VITRO)
}

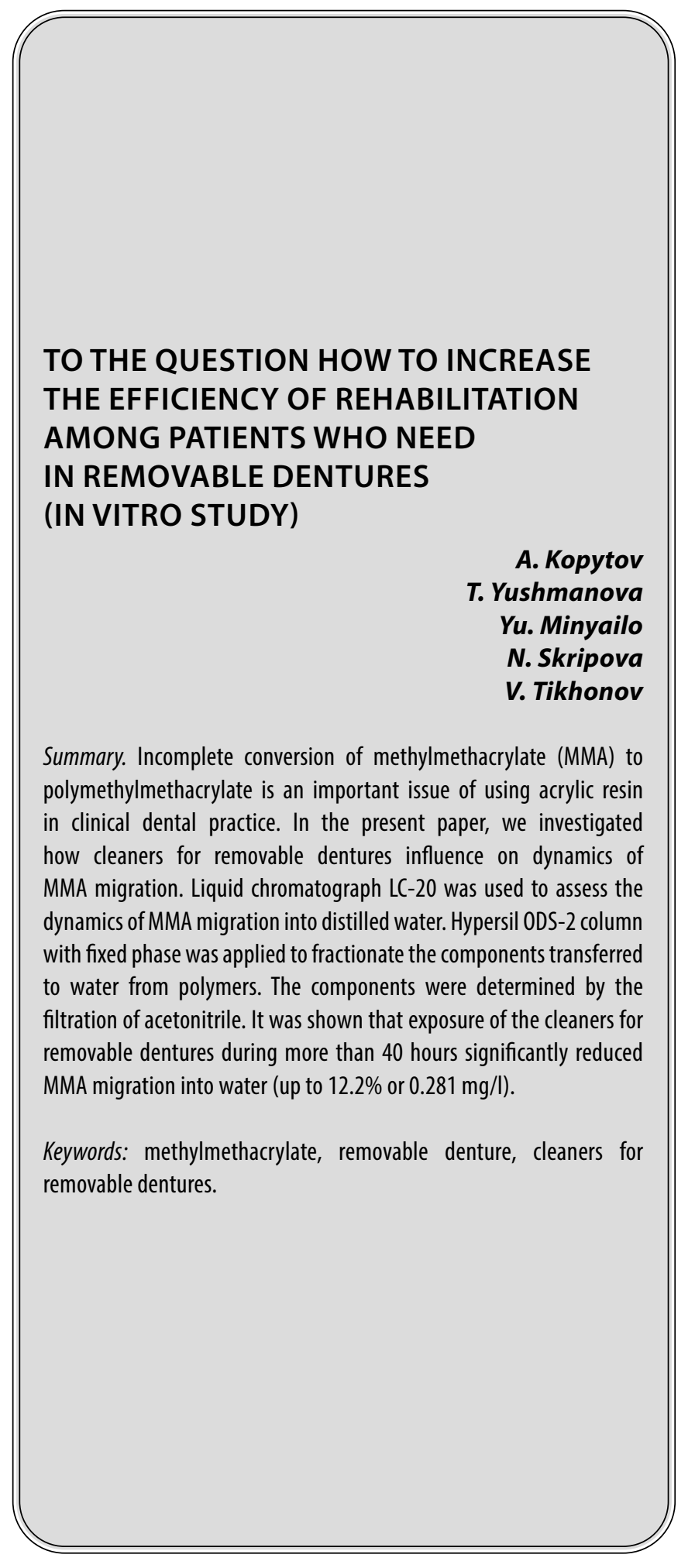

Копытов Александр Александрович

Д.м.н., к.С.н., профессор, ФГАОУ ВО «Белгородский государственный национальный исследовательский университет» (НИУ «БелГУ») kopitov.aleks@yandex.ru

Юиманова Татьяна Николаевна

Д.м.н., профессор, ФГОУ ВО Минздрава России «Северный государственный медицинский университет», г. Архангельск (СГМУ, г. Архангельск) yushmanovatn@yandex.ru

Миняйло Юрий Анатольевич

Ассистент, ФГАОУ ВО «Белгородский государственный национальный исследовательский университет» (НИУ «БелГУ») kopitov.aleks@yandex.ru

Скрипова Наталья Владимировна К.м.н., доцент, ФГОУ ВО Минздрава России «Северный государственный медицинский университет», г. Архангельск (СГМУ, г. Архангельск) snv-nord@yandex.ru

Тихонов Владимир Николаевич

Ассистент, ФГОУ ВО Минздрава России «Северный государственный медицинский университет»,

г. Архангельск (СГМУ, г. Архангельск) yushmanowa.tatiana@yandex.ru

Аннотация. Одной из серьёзнейших проблем, связанных с клиническим применением акриловых пластмасс, является неполное превращение метилметакрилата В полиметилметакрилат. В статье представлены данные 0 влиянии средств для поддержания гигиены съёмных протезов на динамику миграции остаточного мономера метилметакрилата. Оценка динамики миграции в дистиллированную воду мономера метилметакрилата (ММА) осуществлялась с использованием жидкостного хроматофографа LC-20. Фракционирование компонентов, перешедших в воду из базисных полимеров, проведено при помощи колонки с неподвижной фазой Hypersil ODS-2. Доставку компонентов обусловила фильтрация ацетонитрила. Доказано, что воздействие компонентов средств для очистки зубных протезов на акриловые полимеры с экспозицией, превышающей 40 часов, достоверным образом снижает миграцию метилметакрилата в водные вытяжки (д012,2\% или 0,281мг/л).

Ключевые слова: метилметакрилат, съёмный пластиночный протез, средства для очистки съёмных протезов. 


\section{Актуальность}

A криловые пластмассы горячего отверждения относятся к материалам, наиболее часто применяемым для изготовления базисов частичных и полных съёмных протезов. Компонентами этих материалов являются частицы полиметилметакрилата, смешиваемого с мономером метилметакрилатом, реакция полимеризации проходит на фоне воздействия температуры в присутствии соответствующих сшивающих агентов [4,5]. При этом мигрирующий в ротовую жидкость остаточный метилметакрилат негативно воздействует на ткани протезного ложа, осложняя реабилитацию пациентов с частичным и полным отсутствием зубов. Известно, что акриловые пластмассы характеризуются незначительным водопоглощением, что предполагает возможность диффузии веществ, растворённых в воде, в поровое пространство базиса. Также известны рекомендации по уходу за протезами и очистке их от остатков пищи и микробного налёта методом погружения в воду с растворёнными в ней специальными таблетками.

В связи с повышением среднего возраста населения особую значимость обретают исследования, направленные на разработку алгоритмов, снижающих повреждающее воздействие на организм компонентов съёмных пластиночных протезов. Ставя целью скорейшее достижение реабилитации, следует учитывать, что пациенты старших возрастных групп не всегда способны поддерживать на хорошем уровне гигиену съёмных пластиночных протезов. Обеспечение гигиены съёмных протезов может осуществляться с реализацией двух основных подходов: «механического» и «химического». При этом особую сложность выполнения гигиенических мероприятий испытывают одинокие больные, страдающие соматической и неврологической патологией [1]. Применение химических препаратов обусловливает искомый гигиенический эффект вне зависимости от общесоматического, психического и иных статусов лиц, страдающих вторичной адентией. К средствам для химической чистки протезов предъявляется целый ряд требований. Они должны быть простыми в использовании, эффективно удалять органические и неорганические вещества с поверхности протезов, обладать бактерицидными и фунгицидными свойствами [2]. Проведённые исследования in vitro и in vivo показали, что химические препараты имеют преимущество над механической чисткой зубных протезов, как более простые в использовании и эффективно снижающие динамику образования биоплёнок [6,7].

В последнее время увеличивается число больных, жалующихся на сложность адаптации к съёмным протезам. Зачастую причиной, обусловливающей длительность реабилитации или полную невозможность восстановления жевательной эффективности, выступает мономер метилметакрилат, диффундирующий в ротовую жидкость из базиса съёмного протеза. В свою очередь, ингредиенты средств для химической очистки протезов могут, выравнивая концентрацию, диффундировать в поровую систему базиса протеза. Наше предположение подтверждается требованиями ГОСТа, устанавливающими возможное во-

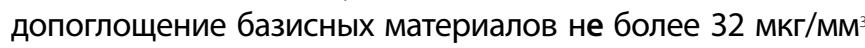

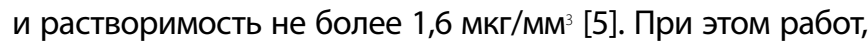
посвящённых воздействию активных веществ, являющихся компонентами гигиенических средств, на остаточный мономер метилметакрилат, в доступной литературе недостаточно.

\section{Цель исслеАования}

Оценить влияние средств ухода за зубными протезами на динамику миграции метилметакрилата из акриловых базисных материалов.

\section{Материалы и метолы}

К исследованию приняты три материала для изготовления базисов съёмных протезов «Фторакс», «Белакрил метилметакрилат горячего отверждения» (БМГО) и «Белакрил этилметакрилат горячего отверждения» (БЭГО). Средствами, выбранными для подтверждения или опровержения гипотезы о влиянии гигиенических препаратов на динамику миграции метилметакрилата, приняты таблетки «Dentipur» и «Protefix Активный».

Проведению исследования предшествовало определение корреляционной массы базисных материалов и модельной среды (дистиллированной воды), необходимой для проведения исследований согласно ГОСТа [3]. Оценка динамики миграции в дистиллированную воду мономера метилметакрилата (ММА) осуществлялась с использованием жидкостного хроматофографа LC-20, в состав которого входил насос высокого давления LC-20 AD и спектрофотометрический детектор SPD-20 AV. Фракционирование компонентов, перешедших в воду из базисных полимеров, проведено при помощи колонки с неподвижной фазой Hypersil ODS-2, наполненной сорбентом, гранулометрически соответствующим размеру 5 мкм. Доставку компонентов обусловила фильтрация ацетонитрила, перемещающегося со скоростью 1 мл/мин.

Для проведения исследования методом горячей полимеризации изготовлено по 43 полоски каждого материала с размерами 40,0 $11,0 \times 10,0 \pm 0,5 \times 2,0 \pm 0,1$ мм. После последовательного шлифования и полирования полоски распиливались. Для каждого материала готовилось 9 колб, в каждую из которых помещали по 9,5 полосок. На протяжении исследования все колбы с дистиллированной водой, взятой в объёме 250 мл, подвергались термостатированию при температуре $37 \pm 1{ }^{\circ} \mathrm{C}$. Колбы каждого из материалов, случайным образом были разделены на три группы, по три 
колбы в каждой: одну контрольную и две испытуемые. В испытуемые колбы, моделируя воздействие на базис протезов гигиенических средств, добавляли таблетки «Dentipur» и «Protefix Активный».

В контрольных группах образцы каждого из материалов заливались только дистиллированной водой. Имитируя погружение протеза в раствор с гигиеническим средством на одну ночь, в контрольные колбы заливалась дистиллированная вода, через 6 часов вода сливалась. Затем образцы заливались новой порцией дистиллированной воды, и через следующие 24 часа проводилась обращенно-фазовая высокоэффективная жидкостная хроматография (ВЭЖХ), показывающая концентрацию ММА в вытяжке.

На следующем этапе, моделируя погружение протеза в раствор с гигиеническим средством на 3 ночи, в контрольные колбы заливалась новая порция воды. После 18 часовой экспозиции вода сливалась, а образцы заливались на трое суток новой порцией воды. Трёхсуточная вытяжка подвергалась хроматографии. Без интервала, моделируя семисуточные гигиенические мероприятия, в контрольные колбы наливалась дистиллированная вода на 42 часа. По истечению срока вода сливалась, наливалась новая порция, оценка количества мигрировавшего в воду ММА проводилась через 7 суток.

На последнем этапе образцы, находящиеся в контрольных пробирках, заливались дистиллированной водой на 84 часа, что соответствовало четырнадцатисуточным ночным гигиеническим мероприятиям. Слитую воду заменяли новой порцией и через 14 суток оценивали концентрацию мигрировавшего в воду ММА.

В последующем три колбы каждого материала объединили в первую испытуемую группу. В этой группе перед получением одно- трёх- семи- и четырнадцатисуточных вытяжек образцы контактировали на протяжении 6, 18, 42 и 84 часов с раствором, содержащим таблетки для поддержания гигиены съёмных протезов «Dentipur». Такое погружение позволяло моделировать нахождение протезов в чистящем растворе одну, три, семь и четырнадцати ночей. Первая экспозиция, моделирующая ночное нахождение протеза в растворе «Dentipur», составила 6 часов. Затем раствор сливался, в колбу наливалось дистиллированная вода, в которую погружались образцы на 24 часа, после чего проводилась ВЭЖХ вытяжки. Без интервала В колбы наливали следующие 250 мл воды, в которой растворяли таблетки «Dentipur», экспозиция воздействия гигиенического средства составила 18 часов, что соответствует трёхсуточным ночным гигиеническим мероприятиям. По истечению заданного времени раствор «Dentipur» сливали, и заливали образцы дистиллированной водой. Время, после которого проводили оценку концентрации
ММА, составило 3 суток. Таким же образом, моделируя воздействие гигиенического средства «Dentipur» на миграцию мономера, образцы погружали в раствор гигиенического средства на 42 и 84 часа, что имитировало гигиеническую обработку протезов в течение 7 и 14 ночей соответственно. После 48-часовой и 84-часовой выдержки растворы «Dentipur» сливались, в колбы наливалась дистиллированная вода, и через 7 и 14 суток соответственно оценивалась концентрация ММА в модельной среде. Применение этого алгоритма позволило оценить влияние на миграцию ММА в водные вытяжки таблетированного очистителя зубных протезов «Protefix Активный».

\section{Результаты исслелований}

По данным ВЭЖХ, сравнительная оценка воздействия средств для очистки зубных протезов «Dentipur» и «Protefix Активный» на интенсивность миграции ММА в одно- трёхсеми- и четырнадцатисуточные водные вытяжки не имеет достоверных отличий ( $>00,05)$. Полученные данные обусловили возможность объединения результатов, полученных при оценке динамики миграции ММА на фоне воздействия «Dentipur» и «Protefix Активный», в одну испытуемую группу, содержащую по 6 колб каждого материала.

В контрольных односуточных вытяжках из пластмассы «Фторакс» концентрация ММА составила 0,112 0,011мг/л, в колбах с образцами, в течение 6-ти часов контактировавшими с гигиеническими средствами, концентрация мономера достигла 0,110 $\pm 0,012$ мг/л, что меньше на 1,8\% концентрации в контрольной вытяжке.

В контрольных вытяжках из пластмасс БМГО и БЭГО кон-

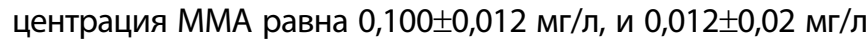
соответственно. Предварительная 6-ти часовая экспозиция образцов в растворе средств для гигиены протезов не привела к снижению количества остаточного мономера. Сравнительная оценка концентрации ММА в контрольных вытяжках и в вытяжках, полученных после воздействия на образцы средств для очистки протезов, не выявила достоверных отличий $(\mathrm{p}>0,05)$.

После трёхсуточного термостатирования в вытяжках из образцов пластмассы «Фторакс», погруженных в контрольные пробирки, концентрация ММА увеличилась

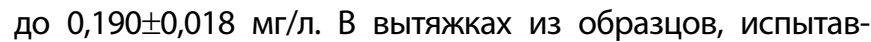
ших моделирование ситуации «погружения на три ночи в гигиенический раствор», концентрация ММА по сравнению с контрольной была меньше на $3,2 \%$ и составила $0,184 \pm 0,018 \mathrm{мг/л.}$

В контрольных вытяжках из пластмасы БМГО ММА присутствует в концентрации 0,119 $\pm 0,002$ мг/л. Контакт образцов с гигиеническим средством снизил концентра-

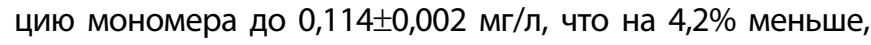


чем в контрольных пробирках. В контрольных вытяжках и в вытяжках, полученных после 18 часового нахождения образцов в растворе гигиенических средств, концентрация ММА соответствовала 0,020 $\pm 0,002$ мг/л. После моделирования ситуации погружения акрилового протеза в гигиенический раствор на три ночи выявлено недостоверное снижение ММА в вытяжках из пластмасс «Фторакс» и БМГО ( $>0,05)$. В контрольных и испытуемых вытяжках из пластмассы БЭГО изменения динамики миграции ММА не выявлено.

Содержание ММА в контрольных вытяжках после семисуточного термостатирования образцов пластмассы «Фто-

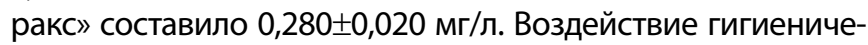
ских средств на образцы базисной пластмассы «Фторакс» привело к снижению концентрации мономера на 7,9\%

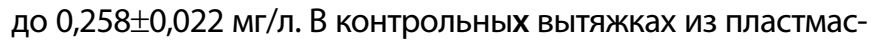
сы БМГО экстрагируемый ММА обнаружен в количестве

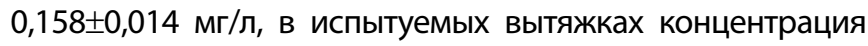

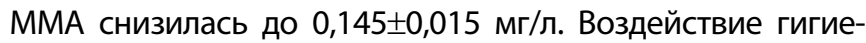
нических средств снизило концентрацию ММА на 8,2\%. Разница количества ММА после семисуточного термостатирования БЭГО составила 7,1\% при его концентрации в контрольной вытяжке 0,028 $\pm 0,007$ мг/л и в испытуемых вытяжках 0,026士0,007 мг/л. Воздействие средств для очистки зубных протезов в течение 42 часов привело к достоверному снижению концентрации ММА в вытяжках из образцов акриловых пластмасс $(p<0,05)$.

В четырнадцатисуточных вытяжках, полученных из контрольных колб, содержащих образцы «Фторакс»,

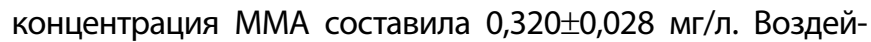
ствие на образцы гигиенических средств привело к сни- жению количества ММА в испытуемых вытяжках на 12,2\% до 0,281 $\pm 0,028$ мг/л. В контрольных вытяжках из пластмассы БМГО выявлено присутствие ММА в количестве $0,188 \pm 0,022 \mathrm{мг/л.}$

Восьмидесятичетырёхчасовое нахождение образцов пластмассы БМГО привело к сокращению концентрации ММА на 11,7\% до 0,166 $\pm 0,024$ мг/л. В контрольных вытяжках из пластмассы ЭМГО количество ММА соответствовало 0,036 $\pm 0,003$ мг/л. Присутствие в колбах, содержащих испытуемые вытяжки, гигиенических средств привело к уменьшению концентрации мономера на 8,33\% до $0,033 \pm 0,003$ мг/л.

Средства для очистки зубных протезов, воздействуя в течение 84 часов на образцы акриловых пластмасс, достоверном образом снижают концентрацию ММА в водных вытяжках $(p<0,05)$.

\section{ВыВОАы}

Воздействие компонентов средств для очистки зубных протезов на акриловые полимеры с экспозицией, превышающей 40 часов, достоверным образом снижает миграцию метилметакрилата в водные вытяжки.

Вне зависимости от возможности стоматологических больных поддерживать гигиеническое состояние съёмных протезов им следует рекомендовать проведение гигиенических процедур с применением средств для очистки зубных протезов, что снижает миграцию метилметакрилата, характеризующегося выраженным раздражающим и токсическим воздействием.

\section{ЛИТЕРАТУРА}

1. Копытов А.А., Московская Н. Б. Воздействие продуктов быстрого приготовления на биоценоз зубодесневого кармана, повреждённого пародонтологической терапией // Научные ведомости Белгородского государственного университета. Серия: Медицина. Фармация. 2011. № 10 (105). С. $231-235$.

2. Миняйло Ю.А., Копытов А. А., Поздняков С. Н. Основные этапы развития материалов и методов изготовления базисов съемных протезов // Клиническая стоматология. 2021. № 1 (97). С. 124-130.

3. Оценка биологического действия медицинских стоматологических материалов и изделий. Классификация и приготовление проб]: гоСт 31576-2012.Введ. 2015-01-01. Москва: Стандартинформ, 2013. 11 с.

4. Юшманова Т.Н., Скрипова Н. В. Клиническое материаловедение. Сплавы металлов и полимерные материалы, применяемые в ортопедической стоматологии: учебное пособие/ Т. Н. Юшманова, Н. В. Скрипова.— Архангельск: Изд-во Северного государственного медицинского университета, 2020. - 122 с.

5. Юшманова Т.Н., Скрипова Н. В., Поливаная Е. А., Сивков А. Н. Стоматологическое материаловедение: учебное пособие.- Архангельск: Изд-во Северного государственного медицинского университета, 2019. - 234c.

6. Gornitsky M, Paradis I, Landaverde G, Malo AM, Velly AM. A clinical and microbiological evaluation of denture cleansers for geriatric patients in long-term care institutions.// J. Can Dent Assoc. 2002;68:39-45.

7. Jagger D.C, Al-Akhazam L, Harrison A, Rees JS. The effectiveness of seven denture cleansers on tea stain removal from PMMA acrylic resin.//Int. J Prosthodont 2002;15:549-552.

( К Копытов Александр Александрович ( kopitov.aleks@yandex.ru ), Юшманова Татьяна Николаевна ( yushmanovatn@yandex.ru ),

Миняйло Юрий Анатольевич (kopitov.aleks@yandex.ru), Скрипова Наталья Владимировна ( snv-nord@yandex.ru ),

Тихонов Владимир Николаевич ( yushmanowa.tatiana@yandex.ru).

Журнал «Современная наука: актуальные проблемы теории и практики» 